\title{
Diversity and Plant Growth-Promoting Effects of Fungal Endophytes Isolated from Salt-Tolerant Plants
}

\author{
Irina Khalmuratova ${ }^{1 \dagger}$, Doo-Ho Choi ${ }^{1 \dagger}$, Ju-Ri Woo ${ }^{1}$, Min-Ji Jeong ${ }^{1}$, Yoosun Oh ${ }^{1}$, Young-Guk Kim ${ }^{1}$, \\ In-Jung Lee ${ }^{2}$, Yeon-Sik $\mathrm{Choo}^{3}$, and Jong-Guk Kim ${ }^{1 *}$ \\ ${ }^{1}$ School of Life Science and Biotechnology, Kyungpook National University, Daegu 41566, Republic of Korea \\ ${ }^{2}$ School of Applied Biosciences, Kyungpook National University, Daegu 41566, Republic of Korea \\ ${ }^{3}$ Department of Biology, College of National Sciences, Kyungpook National University, Daegu 41566, Republic of \\ Korea
}

Fungal endophytes are symbiotic microorganisms that are often found in asymptomatic plants. This study describes the genetic diversity of the fungal endophytes isolated from the roots of plants sampled from the west coast of Korea. Five halophytic plant species, Limonium tetragonum, Suaeda australis, Suaeda maritima, Suaeda glauca Bunge, and Phragmites australis, were collected from a salt marsh in Gochang and used to isolate and identify culturable, root-associated endophytic fungi. The fungal internal transcribed spacer (ITS) region ITS1-5.8S-ITS2 was used as the DNA barcode for the classification of these specimens. In total, 156 isolates of the fungal strains were identified and categorized into 23 genera and two phyla (Ascomycota and Basidiomycota), with Dothideomycetes and Sordariomycetes as the predominant classes. The genus Alternaria accounted for the largest number of strains, followed by Cladosporium and Fusarium. The highest diversity index was obtained from the endophytic fungal group associated with the plant $P$. australis. Waito-C rice seedlings were treated with the fungal culture filtrates to analyze their plant growth-promoting capacity. A bioassay of the Sm-3-7-5 fungal strain isolated from S. maritima confirmed that it had the highest plant growth-promoting capacity. Molecular identification of the Sm-3-7-5 strain revealed that it belongs to Alternaria alternata and is a producer of gibberellins. These findings provided a fundamental basis for understanding the symbiotic interactions between plants and fungi.

Keywords: Halophytic plants, endophytic fungi, diversity, salt marsh, plant growth promotion, gibberellins

Received: July 1, 2020 Accepted: August 28, 2020 First published online: August 31, 2020

*Corresponding author Phone: +82-53-950-5379 Fax: +82-53-955-5379 E-mail: kimjg@knu.ac.kr

${ }^{\dagger}$ These authors contributed equally to this work.

Supplementary data for this paper are available on-line only at http://jmb.or.kr.

pISSN 1017-7825 elSSN 1738-8872

Copyright(C) 2020 by The Korean Society for Microbiology and Biotechnology

\section{Introduction}

Unique microecosystems within the internal tissues of plants support diverse, symbiotic microbial communities that greatly influence plant adaptation and evolution $[1,2]$. These microbial associations significantly influence the ability of plants to adapt and evolve in their environment. All plants in natural ecosystems appear to develop symbiotic associations with fungi $[3,4]$. These symbioses provide a buffer against biotic and abiotic stresses and are important for the survival of plant hosts and their fungal symbionts in highstress habitats $[3,4]$. Both plant and fungi obtain multiple benefits from symbiotic interactions in terms of fitness. Fungal symbionts may impart beneficial (mutualism, commensalism, and parasitism), harmful (competition), or neutral (amensalism and neutralism) activities on the plant host. Concurrently, host plants can also interact beneficially (mutualism), neutrally (commensalism and neutralism), or harmfully (parasitism, competition, and amensalism) during symbiosis with the fungi [5-7].

Microbes living within plants are referred to as 'endophytes' and are host-specific fungi or bacteria, such as Actinomycetes spp. $[8,9]$. Endophytes constitute a major portion of the fungal symbionts associated with the roots, stems, and leaves of plants, and generally do not impart adverse effects to the host $[10,11]$. They comprise a diverse group and represent a wide taxonomical range of fungi belonging primarily to the phylum Ascomycota $[12,13]$. Some fungal endophytes can synthesize plant growth hormones such as auxin, abscisic acid, and gibberellins (GAs) $[14,15]$. Endophytic fungi increase the host's resistance to biotic stresses caused by insects, pests, and fungal pathogens and improve the host plant's fitness against harsh environmental factors [16].

A large percentage of the world's biodiversity is concentrated within the coastal regions, although much of it is yet to be discovered. The coastal zone is the interface between the land and sea and is characterized by interconnections among neighboring ecosystems. Coastal salt marsh wetlands, located in this transition zone between land and salt or brackish water, are among the most important and biologically productive natural ecosystems on 
Earth,. These coastal wetlands provide several ecosystem services, such as nutrient removal, storm protection, and carbon sequestration. However, the harsh coastal environment can also inhibit plant growth due to tidal submergence, anaerobic soil (little or no oxygen present), and high salinity [17, 18]. Moreover, anthropogenic activities contribute significantly to the destruction of salt marsh habitats $[19,20]$.

This study sought to isolate and identify members of the endophytic fungal community from the roots of halophytic plants, and provide analysis of their diversity and distribution. This work also uses a bioassay of the endophytic fungal isolates applied to Waito-C rice seedlings to observe the effects of plant growth promotion and GA production.

\section{Materials and Methods \\ Collection of Plant Samples}

Samples from five mature and healthy plant species, Limonium tetragonum, Suaeda australis, Suaeda maritima, Suaeda glauca Bunge, and Phragmites australis, from the Gochang salt marsh located on the west coast of Korea, were collected for this study. The sampling sites and scientific names of the five halophytes are listed in Table 1. All samples were immediately placed individually in sterile plastic bags and stored at $4^{\circ} \mathrm{C}$ upon arrival at the laboratory. Plants were processed within $48 \mathrm{~h}$ of being sampled.

\section{Surface Sterilization and Isolation of Endophytic Fungi from Root Samples}

Prior to sterilization, the root samples were thoroughly washed in running tap water to remove sand particles, soil, and other debris. The roots were subjected to a three-step surface sterilization procedure, treated with Tween 80 solution $(200 \mu \mathrm{l}$ in $100 \mathrm{ml}$ distilled water) for $10 \mathrm{~min}$ and twice with $1 \%(\mathrm{w} / \mathrm{v})$ perchloric acid solution for $10 \mathrm{~min}$, followed by washing with distilled water [21-24]. Following these preprocessing steps, the roots were aseptically sectioned into 1.5-2-cm-long fragments. Finally, the plant fragments were transferred onto the isolation media (Hagem minimal medium: $0.5 \%$ glucose, $0.05 \% \mathrm{KH}_{2} \mathrm{PO}_{4}, 0.05 \% \mathrm{MgSO}_{4} \cdot 7 \mathrm{H}_{2} \mathrm{O}, 0.05 \% \mathrm{NH}_{4} \mathrm{Cl}$, and $0.1 \% \mathrm{FeCl}_{3}$ ) containing $80 \mathrm{ppm}$ streptomycin and incubated at $25^{\circ} \mathrm{C}$ [25-27]. All fungi that grew from the inside of the root samples were then transferred onto potato dextrose agar. The isolated pure cultures of root fungi were stored on potato dextrose agar plates and slants [21-23].

\section{DNA Extraction, PCR Amplification, and Identification of Fungal Strains}

The mycelia of the fungal strains were cultivated in potato dextrose broth for $7-10$ days at $120 \mathrm{rpm}$ and $25^{\circ} \mathrm{C}$. The lyophilized fungal strains were used for identification. The fungal genomic DNA was extracted with a DNeasy Plant Mini Kit (Qiagen, USA) and the internal transcribed spacer (ITS) region of the DNA was amplified using universal primers ITS-1 (5' - TCC GTA GGT GAA CCT GCG G-3') and ITS-4 (5' - TCC GCT TAT TGA TAT GC$3^{\prime}$ ). The reaction conditions consisted of an initial denaturation at $95^{\circ} \mathrm{C}$ for $2 \mathrm{~min}$, followed by 35 cycles of denaturation at $95^{\circ} \mathrm{C}$ for $30 \mathrm{sec}$, annealing at $55^{\circ} \mathrm{C}$ for $1 \mathrm{~min}$, and extension at $72^{\circ} \mathrm{C}$ for $1 \mathrm{~min}$, and a final extension at $72^{\circ} \mathrm{C}$ for $7 \mathrm{~min}$. The PCR products were observed by agarose gel electrophoresis with ethidium bromide staining. The products were purified with a QIAGEN QIAquick PCR Purification Kit and sequenced using the ABI PRISM BigDye Terminator Cycle Sequencing Kit (Applied Biosystems, USA) on an ABI 310 DNA sequencer (Perkin-Elmer). The resulting DNA sequence was identified using the Basic Local Alignment Search Tool (BLAST) search program (http://www.ncbi.nlm.gov/BLAST/) from the National Center for Biotechnology Information (NCBI).

\section{Statistical Analysis}

The generic richness and diversity of the fungal endophytes were analyzed at the genus level in the plant samples. Menhinick's index $(D m n)$ and Margalef's index $(D m g)$ were used to determine the richness of each genus in the community [28-29]. The Menhinick's index was calculated via the following equation: $\mathrm{Dmm}=\mathrm{S} / \sqrt{N}$; Margalef's index was calculated as follows: $\operatorname{Dmg}=(\mathrm{S}-1) / \ln (\mathrm{N})$, where $\mathrm{S}$ is the number of genera in a sample, and $\mathrm{N}$ is the total number of individuals in a community. Both indices ranged from 0 to $\infty$. The genus diversity was evaluated using the Shannon diversity index $\left(H^{\prime}\right)$, Fisher's alpha index $(\alpha)$, and Simpson's index of diversity [3031]. Fisher's alpha index ( $\alpha$ ) was calculated as $S=\alpha \cdot \ln (1+N / \alpha)$, where $S$ is the number of genera, and $N$ is the total number of individuals. The equation for Shannon's diversity index is $\mathrm{H}^{\prime}=-\sum_{i=1}^{R} p i \cdot \ln p i$, where $p i$ is the proportion of individuals found in genera $i$ in a sample. The values of the Shannon diversity index generally fall between 1.5 and 3.5. Simpson's index of diversity $(1-D)$ was calculated as $D=\sum_{i=1}^{R} n i(n i-1) / N(N-1)$, where $N$ is the total number of individuals in a sample, and $n i$ is the number of individuals found in genera $i$ in a sample. The magnitude of this index ranges between 0 and 1 ; the greater the magnitude, the greater the sample diversity.

Table 1. Geographic coordinates and scientific names of the plants native to the Gochang salt marsh.

\begin{tabular}{|c|c|c|c|c|}
\hline No. & Plant name & Plant code & Site of collection & Habitat \\
\hline 1 & Limonium tetragonum & $L t$ & $\mathrm{~N} 35^{\circ} 31^{\prime} 52.48^{\prime \prime} / \mathrm{E} 126^{\circ} 31^{\prime} 52.04^{\prime \prime}$ & Halophytic \\
\hline 2 & Suaeda australis & $\mathrm{Sa}$ & $\mathrm{N} 35^{\circ} 32^{\prime} 1.87^{\prime \prime} / \mathrm{E} 126^{\circ} 32^{\prime} 6.37^{\prime \prime}$ & Halophytic \\
\hline 3 & Suaeda maritima & $S m$ & $\mathrm{~N} 35^{\circ} 32^{\prime} 2.16^{\prime \prime} / \mathrm{E} 126^{\circ} 32^{\prime} 5.90^{\prime \prime}$ & Halophytic \\
\hline 4 & Suaeda glauca Bunge & Su & $\mathrm{N} 35^{\circ} 32^{\prime} 1.87^{\prime \prime} / \mathrm{E} 126^{\circ} 32^{\prime} 7.45^{\prime \prime}$ & Halophytic \\
\hline 5 & Phragmites australis & $\mathrm{Pa}$ & $\mathrm{N} 35^{\circ} 32^{\prime} 2.43^{\prime \prime} / \mathrm{E} 126^{\circ} 32^{\prime} 6.05^{\prime \prime}$ & Halophytic \\
\hline
\end{tabular}


Effect of Fungal Filtrates for Plant Growth Promotion in Waito-C Rice Seedlings

The culture filtrates of the isolated fungal strains were bioassayed in Waito-C rice seedlings to determine their plant growth-promoting activity. The fungal isolates were grown in a shaking incubator for 7 days at $25^{\circ} \mathrm{C}$ and 180 $\mathrm{rpm}$ in Czapek broth medium ( $1 \%$ glucose, $1 \%$ peptone, $0.1 \% \mathrm{~K}_{2} \mathrm{HPO}_{4}, 0.05 \% \mathrm{KCl}, 0.05 \% \mathrm{MgSO}_{4} \cdot 7 \mathrm{H}_{2} \mathrm{O}$, and $0.001 \% \mathrm{FeSO}_{4} \cdot 7 \mathrm{H}_{2} \mathrm{O} ; / \mathrm{L} \mathrm{pH} 7.3 \pm 0.2$ ). Forty-five milliliters of culture fluid was harvested; the pellet and the supernatant were stored at $-70^{\circ} \mathrm{C}$ and then lyophilized. The lyophilized supernatants were mixed with $1 \mathrm{ml}$ of autoclaved distilled water. The Waito-C rice seeds were treated overnight with uniconazole $20 \mathrm{ppm}$ to minimize the activity of the seed coat gibberellins. The treated Waito-C rice seeds were washed and soaked in autoclaved distilled water until the sprouts emerged. Then the Waito- $\mathrm{C}$ rice seedlings were transplanted into glass tubes containing a $0.6 \%$ water-agar medium and grown in a growth chamber. Ten microliters of the supernatant solution for each fungal culture filtrate was applied to the apical meristem of the Waito-C rice seedlings at the twoleaf stage. One week after treatment, the plant and shoot length were observed and compared with the controls. The controls included culture filtrate of Gibberella fujikuroi, Czapek broth medium, and distilled water [30, 32].

\section{Extraction and Quantification of Gibberellins (GAs) from the Fungal Culture Filtrates}

The culture filtrate of each endophytic fungal isolate was analyzed for the presence of GAs by gas chromatography/mass spectrometry (GC/MS). Endophytic fungal isolates were cultured in $250 \mathrm{ml}$ of Czapek broth medium (containing $1 \%(\mathrm{w} / \mathrm{v})$ glucose and peptone) for 7 days at $25^{\circ} \mathrm{C}$ in a shaking incubator at $180 \mathrm{rpm}$. The extracted GAs were analyzed by reverse-phase C18 high-performance liquid chromatography (HPLC). The fractions were collected and prepared for GC/MS via selected ion monitoring (SIM) (6890N Network GC System, 5973 Network Mass Selective Detector, Agilent Technologies, USA). Following the GC/MS, all data were collected and analyzed. The three major ions of the supplemented $\left[{ }^{2} \mathrm{H}_{2}\right]$ GAs' internal standards and the fungal GAs were monitored simultaneously. The retention time was determined using hydrocarbon standards to calculate the Kovats retention index (KRI) value, while quantification of the GAs was based on peak area ratios of the nondeuterated (extracted) GAs to deuterated GAs [31,33].

\section{Results and Discussion}

\section{Molecular Identification of the Endophytic Fungi}

In total, 156 fungal endophytes, belonging to 26 species and 23 genera, were isolated from the roots of five halophytic plant species native to the Gochang salt marsh. The nucleotide sequence for each strain was submitted to the GenBank database of the National Center for Biotechnology Information (Accession Nos. KP018058KP018213). The fungal similarity scores obtained were at or close to $100 \%$.

Most of the endophytic fungal strains belonged to the phylum Ascomycota (153/156 strains), while the phylum Basidiomycota (3/156 strains) only represented a minor part of the entire fungal community. The class Dothideomycetes (117/156 strains) accounted for the highest number of strains, followed by the classes Sordariomycetes (26/156 strains), Eurotiomycetes (10/156 strains), Ustilaginomycetes (2/156 strains), and Exobasidiomycetes (1/156 strains). At the genus level, Alternaria (52/156) accounted for the largest proportion, followed by Cladosporium (39/156), and Fusarium (16/156).

Taxonomic placement of endophytic fungi in each plant sample was analyzed at the class and genus levels (Fig. 1). Dothideomycetes from the Ascomycota phylum accounted for the highest percentage at the class level, except in the species L. tetragonum. Dothideomycetes accounted for more than half of the fungi in each plant sample. At the genus level, Alternaria (33.3\%) was the most prominent, followed by Cladosporium (25\%) in all of the plant samples except $S$. glauca Bunge, where Cladosporium was the most prominent genus followed by Fusarium (10.2\%). In the plant samples of L. tetragonum, Fusarium was the most prevalent genus. Alternaria was found in all of the plant samples. The proportion of remaining fungal genera was approximately $0.5 \sim 2.5 \%$. A previous study [26,27] reported that the genus Alternaria was the most prominent fungus found in the roots of halophytic plants native to the Buan salt marsh. Fungal species, including those of the genera Fusarium, Penicillium, Alternaria, and Cladosporium, which are abundant in the host, occasionally establish endophytic associations with plants [34-38].

The current study isolated 156 fungal endophytes from salt-tolerant plants that were identified at the genus level and included Alternaria, Aspergillus, Cladosporium, Cochliobolus, Colletotrichum, Epicoccum, Exophiala, Fusarium, Kabatiella, Khuskia, Lecanicillium, Macrophoma, Meira, Paraconiothyrium, Paraphaeosphaeria, Penicillium, Pestalotiopsis, Phomopsis, Pleospora, Pseudozyma, Stemphylium, Talaromyces, and Trichoderma. Among the endophytic fungi isolated, the genera Alternaria, Cladosporium, and Fusarium were the most abundantly distributed in the plant samples. The phyla of various endophytic fungi were confirmed to be Ascomycota and Basidiomycota. These findings revealed that the roots of the plants growing in the coastal salt marsh are inhabited by diverse endophytic mycobiota.

Molecular techniques and sequencing of the genomic DNA are used widely and successfully for fungal identification [39]. DNA sequence analysis methods provided important information for this study. Most of the ribosomal DNA genes were highly conserved taxonomically for identification. The internal transcribed spacer (ITS) region has been commonly used as a DNA barcode for the molecular identification of fungi. This study was conducted with the $5.8 \mathrm{~S}$ gene and ITS1/2 regions for the identification of the fungal strains [35].

\section{Diversity of the Endophytic Fungi Isolated from Halophytes}

According to the host plant specimen results, the fungal isolates comprised 10 genera and 12 species isolated from L. tetragonum, 7 genera and 9 species from S. australis, 7 genera and 7 species from S. maritima, 8 genera and 


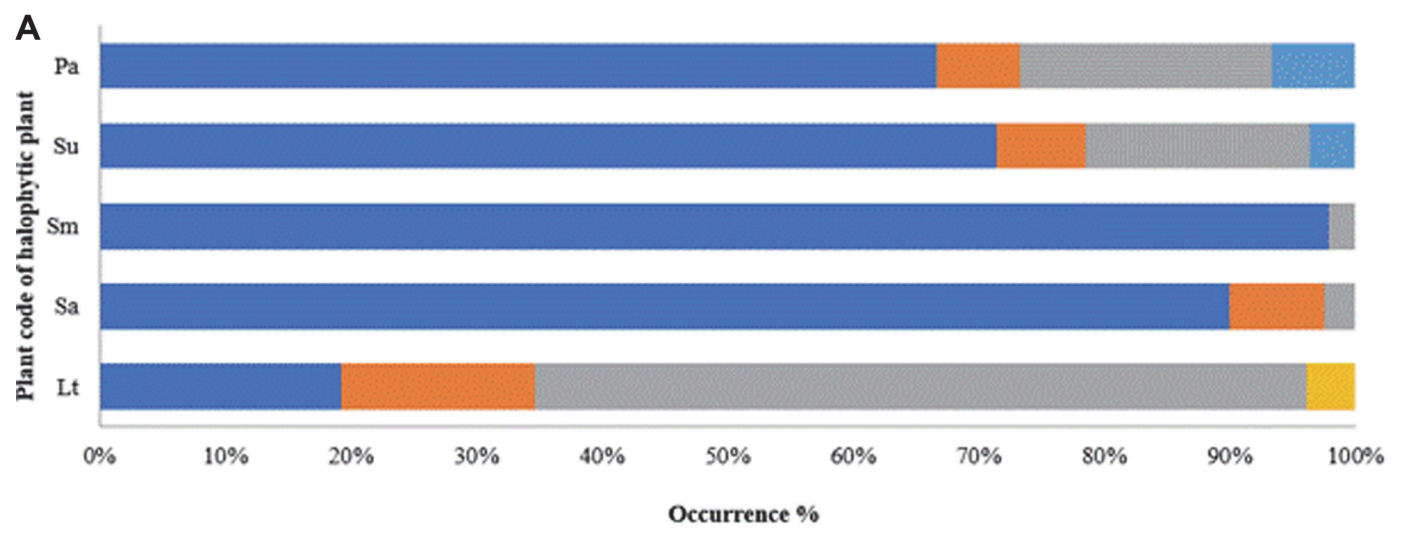

w Dothideomycetes $\equiv$ Eurotiomycetes $\equiv$ Sordariomycetes $=$ Exobasidiomycetes $\equiv$ Ustilaginomycetes

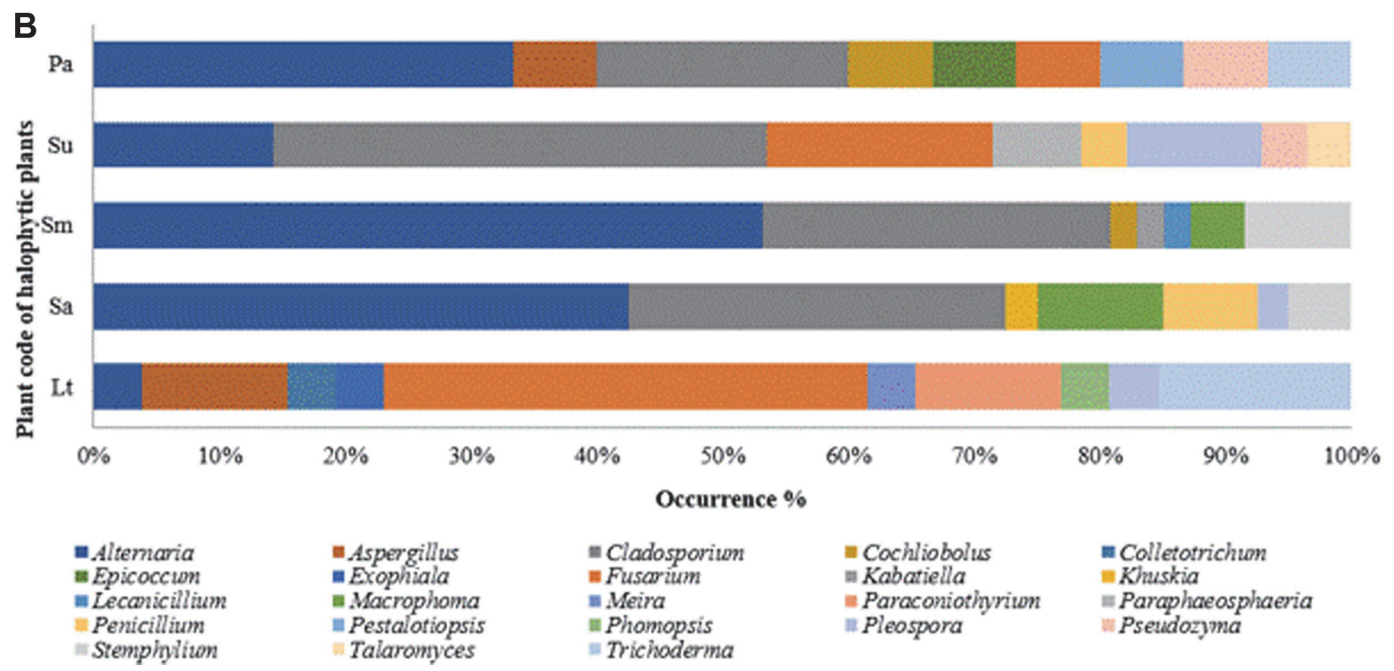

Fig. 1. Distribution of the fungal isolates in different plant samples at the class (A) and genus (B) levels. $L t$, Limonium tetragonum; Sa, Suaeda australis; Sm, Suaeda maritima; Su, Suaeda glauca Bunge; and Pa, Phragmites australis.

6 species from S. glauca Bunge, and 9 genera and 6 species from P. australis (Table 2).

Generic richness and diversity were determined by counting the genera present in the fungal communities among the plant samples (Table 3). P. australis exhibited high scores compared to the other plant species in terms of both genus richness and diversity. Statistical analysis of richness demonstrated that P. australis had a Margalef's index of 2.95 and a Menhinick's index of 2.32. The analysis of genetic diversity revealed a Fisher's $\alpha$ index of 9.50, a Simpson's index of diversity of 0.88 , and Shannon's index of 1.95. Thus, the Shannon index was less sensitive to evenness than the Fisher's $\alpha$ and Simpson's indices [40]. P. australis also exhibited the highest diversity index, as the fungi isolated from this plant were the most diverse compared to the other plant specimens. Statistical analysis of the endophytic fungi via counting the genera from the plant samples revealed that $P$. australis possessed the most diverse type of endophytic fungi. [15].

Fungal symbionts associated with plants in natural ecosystems help plants overcome abiotic stress, such as soil salinity, drought, and heat [41]. Shoreline habitats are frequently exposed to high salt stress, as they remain rhythmically submerged in saltwater. The capacity to resist high salinity stress is necessary for survival in coastal environments. Thus, fungal strains such us Penicillium citrinum and Fusarium oxysporum could improve the

Table 2. Endophytic fungi (156 strains) isolated from five coastal plants with scientific names, plant codes, taxa of fungal strain, and the number of fungal isolates.

\begin{tabular}{cclc}
\hline Scientific name of plant sample & Abbreviated plant name & Taxa of fungal strains & No. of isolates \\
\hline Limonium tetragonum & $\mathrm{Lt}$ & 10 genera, 12 species & 26 \\
Suaeda australis & $\mathrm{Sa}$ & 7 genera, 9 species & 40 \\
Suaeda maritima & $\mathrm{Sm}$ & 7 genera, 7 species & 47 \\
Suaeda glauca Bunge & $\mathrm{Su}$ & 8 genera,6 species & 28 \\
Phragmites australis & $\mathrm{Pa}$ & 9 genera,6 species & 15 \\
\hline
\end{tabular}

Lt, Limonium tetragonum; Sa, Suaeda australis; Sm, Suaeda maritime; Su, Suaeda glauca Bunge; and Pa, Phragmites australis. 
Table 3. Diversity indices and distribution of the endophytic fungi isolated from plants native to the Gochang salt marsh.

\begin{tabular}{|c|c|c|c|c|c|}
\hline Fungal taxon & $\mathrm{Lt}$ & $\mathrm{Sa}$ & $\mathrm{Sm}$ & $\mathrm{Su}$ & $\mathrm{Pa}$ \\
\hline Alternaria & 1 & 17 & 25 & 4 & 5 \\
\hline Aspergillus & 3 & & & & 1 \\
\hline Cladosporium & & 12 & 13 & 11 & 3 \\
\hline Cochliobolus & & & 1 & & 1 \\
\hline Colletotrichum & 1 & & & & \\
\hline Epicoccum & & & & & 1 \\
\hline Exophiala & 1 & & & & \\
\hline Fusarium & 10 & & & 5 & 1 \\
\hline Kabatiella & & & 1 & & \\
\hline Khuskia & & 1 & & & \\
\hline Lecanicillium & & & 1 & & \\
\hline Macrophoma & & 4 & 2 & & \\
\hline Meira & 1 & & & & \\
\hline Paraconiothyrium & 3 & & & & \\
\hline Paraphaeosphaeria & & & & 2 & \\
\hline Penicillium & & 3 & & 1 & \\
\hline Pestalotiopsis & & & & & 1 \\
\hline Phomopsis & 1 & & & & \\
\hline Pleospora & 1 & 1 & & 3 & \\
\hline Pseudozyma & & & & 1 & 1 \\
\hline Stemphylium & & 2 & 4 & & \\
\hline Talaromyces & & & & 1 & \\
\hline Trichoderma & 4 & & & & 1 \\
\hline $\mathrm{N}$ & 26 & 40 & 47 & 28 & 15 \\
\hline S & 10 & 7 & 7 & 8 & 9 \\
\hline Shannon diversity index $\left(H^{\prime}\right)$ & 1.91 & 1.48 & 1.28 & 1.74 & 1.95 \\
\hline Simpson's index of diversity $(1-D)$ & 0.82 & 0.73 & 0.64 & 0.80 & 0.88 \\
\hline Menhinick's index $(D m n)$ & 1.96 & 1.11 & 1.02 & 1.51 & 2.32 \\
\hline Margalef's index (Dmg) & 2.76 & 1.63 & 1.56 & 2.10 & 2.95 \\
\hline Fisher's diversity $(\alpha)$ & 5.95 & 2.46 & 2.28 & 3.74 & 9.50 \\
\hline
\end{tabular}

Lt, Limonium tetragonum; Sa, Suaeda australis; Sm, Suaeda maritime; Su, Suaeda glauca Bunge; and Pa, Phragmites australis

survival and growth of their hosts by enhancing tolerance to environmental stress [10,11,42,43]. Many species of plant symbiotic fungi are known to produce a number of phytohormones [21, 22, 37, 38]. Aspergillus terreus and P. citrinum GAs that confer biotic stress resistance to pathogenic attack [44]. Plant hormones like GAs are essential for many developmental processes in plants, including seed germination, stem elongation, leaf expansion, ripening, and the induction of flowering [45]. Many researchers have found that fungal endophytes could limit the damage caused by pathogenic microorganisms and protect the host from diseases [12, 46, 47]. Moreover, it has been reported that Penicillium species increased salt stress resistance in the host plant $[48,49]$.

Alternaria alternata was the most abundant fungus among the collected samples and was isolated from plants S. australis, S. maritima, S. glauca Bunge, and P. australis. Previous reports have confirmed that A. alternata produces the plant growth regulator indole-acetic acid for the host plant [44] Indole-acetic acids are considered essential for important physiological processes such as cell division or cell elongation, tissue differentiation, phototrophic or geotropic responses, and all subsequent effects on plant growth and development [50]. Moreover, Trichoderma harzianum and $F$. oxysporum could produce indole-acetic acid $[4,51,52]$. Thus, these fungal species helped their host plants procure nutrients and promoted growth.

\section{Screening for Plant Growth-Promoting Effects of Fungal Culture Filtrates on Waito-C Rice Seedlings}

Waito-C seeds were treated with uniconazole as a GA biosynthesis inhibitor. The Sm-3-7-5 fungal strain, which has plant growth-promoting capacity, was analyzed using the Waito-C rice seedlings. Screening of the microbial culture filtrates was used to identify the biologically active molecules to confirm the presence of gibberellins. In this study, plant growth-promoting hormones were detected in the culture filtrates of the fungal endophytes isolated from the roots of the halophytes using the Waito- $\mathrm{C}$ rice seedlings. Waito-C rice is a known dwarf rice cultivar with reduced GA biosynthesis $[7,18]$.

The culture filtrates of all of the fungal endophytes were applied to the Waito- $\mathrm{C}$ rice seedlings to analyze the plant growth promoting capacity (Fig. 2). The culture filtrate treatments using the Sm-3-7-5 fungal strain resulted in a $9.3 \mathrm{~cm}$ shoot length and $19.6 \mathrm{~cm}$ plant length as plant growth-promoting effects. Treatments with $\mathrm{Sm}-3-7-5$ fungal strain or the G. fujikuroi strain revealed marked similarity in plant growth promotion between the two strains. These results were consistent with those of a previous study in which the endophytic fungus Aspergillus clavatus $\mathrm{Y} 2 \mathrm{H} 0002$, isolated from the roots of Nymphoides peltata, was shown to promote the growth of various rice plants [53]. 
A

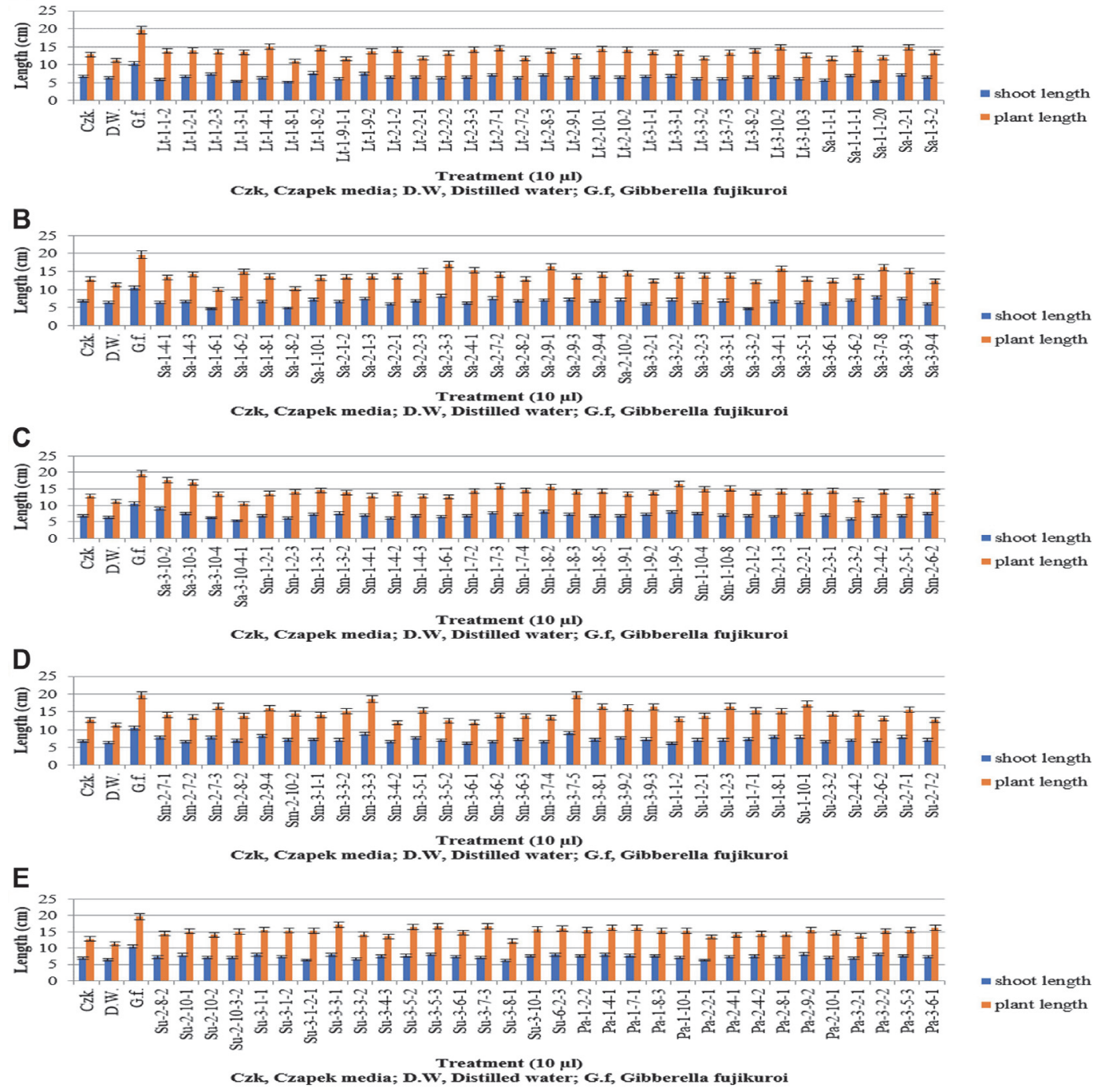

Fig. 2. Waito- $\mathrm{C}$ rice seedlings with fungal culture filtrates of fungal endophytes plant growth promotion results (A, B, C, D, E). Ten microliters of lyophilized culture filtrates were applied to the Waito-C rice seedlings. The shoot length and plant length of the Waito-C rice seedlings were measured following 7 days of treatment. The standard deviation from the means was calculated using Microsoft Excel.

Quantitative Analysis of Culture Filtrate of Sm-3-7-5 for the Presence of Gibberellins

In an analysis of growth promoting effect, Sm-3-7-5 produced the most effective growth promotion results. Comparing with G. fujikuroi, the two strains showed quite similar results in Waito-C growth. Because of that, additional comparison between the two strains was necessary. As GC/MS with selected ion monitoring technique has the ability to analyze highly-complex mixtures and detect compounds of different classes [54], it was used to analyze the culture filtrate of Sm-3-7-5 fungal strain. GC/MS SIM was important for the investigation of a number of compounds and was often used in plant experimentation $[55,56]$. We also employed GC-MS SIM in the quantitative analysis of various plant hormones.

Using HPLC and GC-MS, we analyzed gibberellins produced by fungal endophytes isolated from salt-tolerant plants. A variety of gibberellins were confirmed from the culture filtrate of the Sm-3-7-5 fungal strain; the results of the GC-MS SIM analysis showed that $S \mathrm{~m}-3-7-5$ produced $\mathrm{GA}_{1}(1.820 \mathrm{ng} / \mathrm{ml}), \mathrm{GA}_{3}(2.134 \mathrm{ng} / \mathrm{ml})$, and other inactive $\mathrm{GA}_{9}(0.038 \mathrm{ng} / \mathrm{ml})$ (Fig. 3). We confirmed that $\mathrm{Sm}-3-7-5$ produced as much $\mathrm{GA}_{1}, \mathrm{GA}_{3}$, and $\mathrm{GA}_{9}$ as G. fujikuroi.

In summary, 156 strains of endophytic fungi were isolated from the roots of five halophytic plant species native to the Gochang salt marsh. These halophytes included L. tetragonum, S. australis, S. maritima, S. glauca Bunge, and $P$. australis. A study of the plant growth-promoting effects of A. alternata Sm-3-7-5 and GA production was conducted. All fungal strains were identified by molecular methods and were classified into 2 phyla, 5 classes, 11 orders, 15 families, and 23 genera. Alternaria and Cladosporium were found to be the dominant genera among the collected isolates. The most diverse group of fungi determined by the diversity analysis was isolated from the roots 


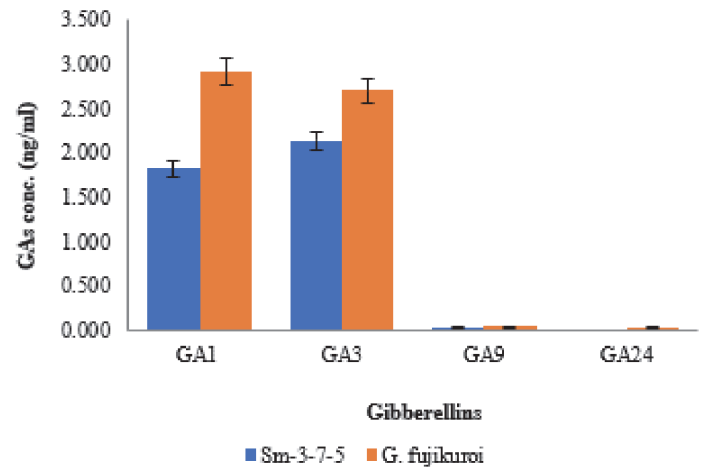

Fig. 3. Gibberellins content of the fungal culture filtrates of the Sm-3-7-5 strain and wild type Gibberella fujikuroi. GC-MS SIM analysis of the culture filtrate extracts from the Sm-3-7-5 fungal strain detected two bioactive GAs. Sm-3-7-5 showed the presence of bioactivity of GA1, GA3, and other inactive GAs. The standard deviation from the means was calculated using Microsoft Excel.

of $P$. australis. In conclusion, this study provides key information to the literature toward understanding the interactions between coastal plants and fungi.

\section{Acknowledgments}

This study was supported by the Ulleungdo Dokdo Research Institute of Kyungpook National University, Korea.

\section{Conflict of Interest}

The authors have no financial conflicts of interest to declare.

\section{References}

1. Barrow JR, Lucero ME, Reyes-Vera I, Havstad KM. 2008. Do symbiotic microbes have a role in regulating plant performance and response to stress?. Commun. Integr. Biol. 1: 69-73.

2. Selosse MA, Baudoin E, Vandenkoornhuyse P. 2004. Symbiotic microorganisms, a key for ecological success and protection of plants. C. R. Biol. 327: 639-648.

3. Rodriguez RJ, Redman RS, Henson JM. 2004. The role of fungal symbioses in the adaptation of plants to high stress environments. Mitig Adapt Strateg Glob Chang 9: 261-272.

4. Thomas F, Morris JT, Wigand C, Sievert SM. 2019. Short-term effect of simulated salt marsh restoration by sand-amendment on sediment bacterial communities. PLoS One 14: e0215767.

5. Rodriguez RJ, Redman RS. 2008. More than 400 million years of evolution and some plants still can't make it on their own: plant stress tolerance via fungal symbiosis. J. Exp. Bot. 59: 1109-1114.

6. Rodriguez RJ, Henson J, Van Volkenburgh E, Hoy M, Wright L, Beckwith F, et al. 2008. Stress tolerance in plants via habitat-adapted symbiosis. ISME J 2: 404-416.

7. Sang-Mo K, Abdul Latif K, Young-Hyun Y, Muhammad K. 2014. Gibberellin production by newly isolated strain Leifsonia soli SE134 and its potential to promote plant growth. J. Microbiol. Biotechnol. 24: 106-112.

8. Nair DN, Padmavathy S. 2014. Impact of endophytic microorganisms on plants, environment and humans. ScientificWorldJournal 2014: 250693.

9. Nalini MS, Sunayana N, Prakash HS. 2014. Endophytic fungal diversity in medicinal plants of western ghats, India. Int. J. Biodivers 2014: Doi: 10.1155/2014/494213.

10. Khan AL, Hamayun M, Kang SM, Kim YH, Jung HY, Lee JH, et al. 2012. Endophytic fungal association via gibberellins and indole acetic acid can improve plant growth under abiotic stress: an example of Paecilomyces formosus LHL10. BMC Microbiol. 12: 3.

11. Khan SA, Hamayun M, Khan AL, Lee IJ, Shinwari ZK, Kim JG. 2012. Isolation of plant growth promoting endophytic fungi from dicots inhabiting coastal sand dunes of Korea. Pak J. Botechnol. 44: 1453-1460.

12. Arnold AE, Mejía LC, Kyllo D, Rojas EI, Maynard Z, Robbins N, et al. 2003. Fungal endophytes limit pathogen damage in a tropical tree. Proc. Natl. Acad. Sci. USA 100: 15649-15654

13. Ernst M, Mendgen KW, Wirsel SG. 2003. Endophytic fungal mutualists: seed-borne Stagonospora spp. enhance reed biomass production in axenic microcosms. Mol. Plant Microbe Interact. 16: 580-587.

14. Kedar A, Rathod D, Yadav A, Agarkar G, Rai M. 2014. Endophytic Phoma sp. isolated from medicinal plants promote the growth of Zea mays. Nusantara Bioscie. 6: 132-139.

15. Kim H, You YH, Yoon H, Seo Y, Kim YE, Choo YS, et al. 2014. Culturable fungal endophytes isolated from the roots of coastal plants inhabiting Korean East Coast. Mycobiol. 42: 100-108.

16. Tayung K, Sarkar M, Baruah P. 2012. Endophytic fungi occurring in Ipomoea carnea tissues and their antimicrobial potentials. Braz. Arch Biol. Technol. 55: 653-660.

17. Redondo-Gómez S, Castillo JM, Luque CJ, Luque T, Figueroa M, Davy AJ. 2007. Fundamental niche differentiation in subspecies of Sarcocornia perennis on a salt marsh elevational gradient. Mar. Ecol. Prog. Ser. 347: 15-20.

18. Ullah I, Khan AR, Jung BK, Khan AL, Lee IJ, Shin JH. 2014. Gibberellins synthesized by the entomopathogenic bacterium, Photorhabdus temperata M1021 as one of the factors of rice plant growth promotion. J. Plant Interact 9: 775-782.

19. Barbier EB, Hacker SD, Kennedy C, Koch EW, Stier AC, Silliman BR. 2011. The value of estuarine and coastal ecosystem services. Ecol. Monogr. 81: 169-193.

20. Cahoon DR, Lynch JC, Roman CT, Schmit JP, Skidds DE. 2019. Evaluating the relationship among wetland vertical development, elevation capital, sea-level rise, and tidal marsh sustainability. Estuaries Coast. 42: 1-15. 
21. Ahmad N, Hamayun M, Khan SA, Khan AL, Lee IJ, Shin DH. 2010. Gibberellin-producing endophytic fungi isolated from Monochoria vaginalis. J. Microbiol. Biotechnol. 20: 1744-1749.

22. Hamayun M, Khan SA, Khan AL, Tang DS, Hussain J, Ahmad B, et al. 2010. Growth promotion of cucumber by pure cultures of gibberellin-producing Phoma sp. GAH7. World J. Microbiol. Biotechnol. 26: 889-894.

23. Hamayun M, Khan SA, Khan AL, Rehman G, Kim YH, Iqbal I, et al. 2010. Gibberellin production and plant growth promotion from pure cultures of Cladosporium sp. MH-6 isolated from cucumber (Cucumis sativus L.). Mycologia 102: 989-995.

24. Yamada A, Ogura T, Degawa Y, Ohmasa M. 2001. Isolation of Tricholoma matsutake and T. bakamatsutake cultures from fieldcollected ectomycorrhizas. Mycoscience 42: 43-50.

25. Vázquez MM, César S, Azcón R, Barea JM. 2000. Interactions between arbuscular mycorrhizal fungi and other microbial inoculants (Azospirillum, Pseudomonas, Trichoderma) and their effects on microbial population and enzyme activities in the rhizosphere of maize plants. Agric., Ecosyst. Environ., Appl. Soil Ecol. 15: 261-272.

26. You YH, Kang SM, Choo YS, Lee JM. 2012. Fungal diversity and plant growth promotion of endophytic fungi from six halophytes in Suncheon Bay. J. Microbiol. Biotechnol. 22: 1549-1556.

27. You YH, Yoon HJ, Seo YG, Kim MA, Shin JH, Lee IJ, et al. 2012. Analysis of Genomic Diversity of Endophytic Fungal Strains Isolated from the Roots of Suaeda japonica and S. maritima for the Restoration of Ecosystems in Buan Salt Marsh. Korean J. Microbiol. Biotechnol. 40: 287 295.

28. Hill TC, Walsh KA, Harris JA, Moffett BF. 2003. Using ecological diversity measures with bacterial communities. FEMS Microbiol. Ecol. 43: 1-11.

29. Wearn JA, Sutton BC, Morley NJ, Gange AC. 2012. Species and organ specificity of fungal endophytes in herbaceous grassland plants. J. Ecol. 100: 1085-1092.

30. Fisher RA, Corbet AS, Williams CB. 1943. The relation between the number of species and the number of individuals in a random sample of an animal population. J. Anim. Ecol. 12: 42-58.

31. Hill MO. 1973. Diversity and evenness: a unifying notation and its consequences. Ecology 54: 427-432.

32. Hughes AR, Cebrian J, Heck K, Goff J, Hanley TC, Scheffel W, et al. 2018. Effects of oil exposure, plant species composition, and plant genotypic diversity on salt marsh and mangrove assemblages. Ecosphere 9: e02207.

33. Choi WY, Rim SO, Lee JH, Lee JM, Lee IJ, Cho KJ, et al. 2005. Isolation of gibberellins-producing fungi from the root of several Sesamum indicum plants. J. Microbiol. Biotechnol. 15: 22-28.

34. De-Aldana BRV, Bills G, Zabalgogeazcoa I. 2013. Are endophytes an important link between airborne spores and allergen exposure?. Fungal Divers. 60: 33-42.

35. Sun X, Guo LD. 2012. Endophytic fungal diversity: review of traditional and molecular techniques. Mycology 3: 65-76.

36. Sun Y, Wang Q, Lu X, Okane I, Kakishima M. 2011. Endophytic fungi associated with two Suaeda species growing in alkaline soil in China. Mycosphere 2: 239-248.

37. You YH, Seo YG, Yoon HJ, Kim H, Khalmuratova I, Rim SO, et al. 2013. Endophytic Fungal Diversity Associated with the Roots of Coastal Sand-dune Plants in the Sindu-ri Coastal Sand Dune, Korea. Korean J. Microbiol. Biotechnol. 41: 300-310.

38. You YH, Yoon H, Kang SM, Woo JR, Choo YS, Lee IJ, et al. 2013. Cadophora malorum Cs-8-1 as a new fungal strain producing gibberellins isolated from Calystegia soldanella. J. Basic Microbiol. 53: 630-634.

39. De-Souza-Sebastianes FL, Romao-Dumaresq AS, Lacava PT, Harakava R, Azevedo JL, De-Melo IS, et al. 2013. Species diversity of culturable endophytic fungi from Brazilian mangrove forests. Curr. Genet. 59: 153-166.

40. Colwell RK. 2009. Biodiversity: concepts, patterns, and measurement. pp.257-263. The Princeton guide to ecology.

41. Singh LP, Gill SS, Tuteja N. 2011. Unraveling the role of fungal symbionts in plant abiotic stress tolerance. Plant Signal Behav 6: 175-191.

42. Khan SA, Hamayun M, Yoon H, Kim HY, Suh SJ, Hwang SK, et al. 2008. Plant growth promotion and Penicillium citrinum. BMC Microbiol. 8: 231.

43. You YH, Hwang JS, Yoon HJ, Khan SA, Rim SO, Bae JJ, et al. 2010. Plant Growth Promotion of Calystegia soldanella and Ischaemum anthephoroides by the Strain Penicillium citrinum KACC43900. J. Life Sci. 20: 1373-1377.

44. Waqas M, Khan AL, Hamayun M, Shahzad R, Kim YH, Choi KS, et al. 2015. Endophytic infection alleviates biotic stress in sunflower through regulation of defence hormones, antioxidants and functional amino acids. Eur. J. Plant Pathol. 141: 803-824.

45. Yamauchi Y, Ogawa M, Kuwahara A, Hanada A, Kamiya Y, Yamaguchi S. 2004. Activation of gibberellin biosynthesis and response pathways by low temperature during imbibition of Arabidopsis thaliana seeds. Plant Cell 16: 367-378.

46. Ganley RJ, Sniezko RA, Newcombe G. 2008. Endophyte-mediated resistance against white pine blister rust in Pinus monticola. For. Ecol. Manage. 255: 2751-2760.

47. Mejía LC, Rojas EI, Maynard Z, Van Bael S, Arnold AE, Hebbar P, et al. 2008. Endophytic fungi as biocontrol agents of Theobroma cacao pathogens. Biol. Control 46: 4-14.

48. Khan AL, Hamayun M, Kim YH, Kang SM, Lee IJ. 2011. Ameliorative symbiosis of endophyte (Penicillium funiculosum LHL06) under salt stress elevated plant growth of Glycine max L. Plant Physiol. Biochem. 49: 852-861.

49. Khan AL, Waqas M, Khan AR, Hussain J, Kang SM, Gilani SA, et al. 2013. Fungal endophyte Penicillium janthinellum LK5 improves growth of ABA-deficient tomato under salinity. World J. Microbiol. Biotechnol. 29: 2133-2144.

50. Teale WD, Paponov IA, Palme K. 2006. Auxin in action: signalling, transport and the control of plant growth and development. Nat. Rev. Mol. Cell Biol. 7: 847-859.

51. Hasan HAH. 2002. Gibberellin and auxin-indole production by plant root-fungi and their biosynthesis under salinity-calcium interaction. Acta Microbiol. Immunol. Hung. 49: 105-118.

52. Zhang F, Yuan J, Yang X, Cui Y, Chen L, Ran W, et al. 2013. Putative Trichoderma harzianum mutant promotes cucumber growth by enhanced production of indole acetic acid and plant colonization. Plant Soil 368: 433-444.

53. You YH, Kwak TW, Kang SM, Lee MC, Kim JG. 2015. Aspergillus clavatus Y2H0002 as a New Endophytic Fungal Strain Producing Gibberellins Isolated from Nymphoides peltata in Fresh Water. Mycobiology 43: 87-91.

54. Kawanade Y, Yamane H, Murayama T, Takahashi N, Nakamura T. 1983. Identification of gibberellin A3 in mycelia of Neurospora crassa. Agric. Biol. Chem. 47: 1693-1694.

55. Hamayun M, Khan SA, Khan MA, Khan AL, Kang SM, Kim SK, et al. 2009. Gibberellin production by pure cultures of a new strain of Aspergillus fumigatus. World J. Microbiol. Biotechnol. 25: 1785-1792.

56. Khan SA, Hamayun M, Kim HY, Yoon HJ, Seo JC, Choo YS, et al. 2009. A new strain of Arthrinium phaeospermum isolated from Carex kobomugi Ohwi is capable of gibberellin production. Biotechnol. Lett. 31:283-287. 